\title{
Assessment of Primary Production and Optical Variability in Shelf and Slope Waters Near Cape Hatteras, North Carolina
}

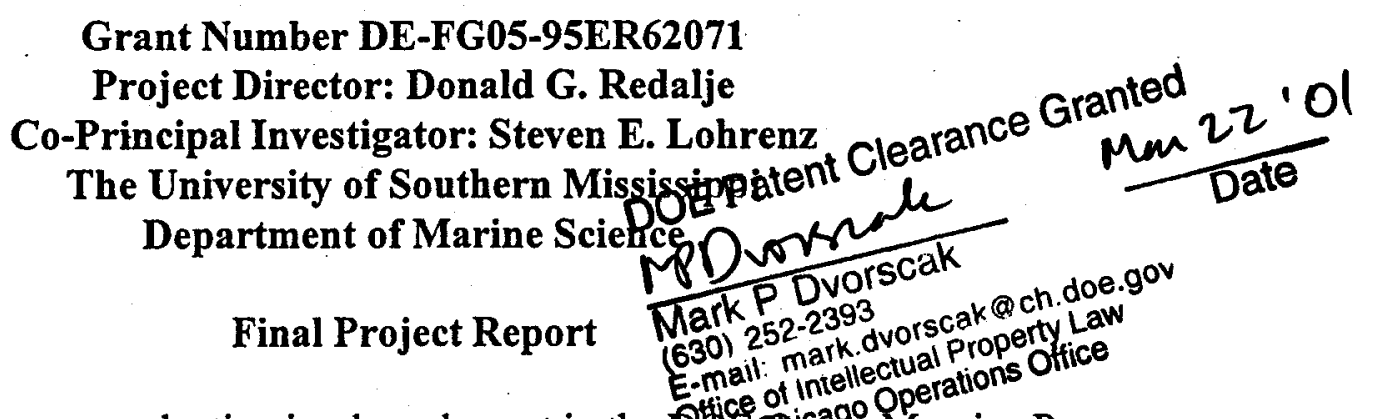

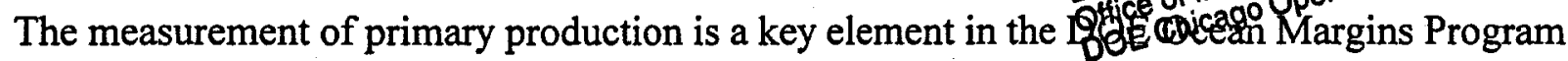
effort to quantify the role of coastal ocean environments in the global $\mathrm{CO}_{2}$ cycle. In particular, OMP has as an objective, the quantification of oceanic uptake of carbon and either its deposition in shelf sediments or its export from the shelf at Cape Hatteras. Our project was the only one within the OMP that conducted direct measurements of the carbon fixation process in the 1996 field study. During Year 2 of this project we took part in 2 research cruises to the Cape Hatteras study region. The first cruise (Cruise EN280 on the R/V Endeavor) took place March 11-21, 1996 and the second cruise (Cruise SJ9607 on the R/V Seward Johnson) took place July 18-27, 1996. During each of these cruises, we were able to acquire sufficient data so that we could successfully address many of the goals of the overall Ocean Margins Program as well as those specific to this project. Several specific tasks have been identified and are being carried out which will help us to address these OMP and project objectives. These tasks are:

- Examine temporal and spatial variability in primary production determined using simulated in situ and photosynthesis-irradiance (P-I) incubations

- Characterize the optical properties (e.g. spectral absorption, spectral beam attenuation, quantum yield) of various parts of the study region to help identify if discrete bio-optical provinces (i.e. regions of similar biological and optical properties where similar modeling parameters can be applied to estimate primary production) occur within the study region so that we can "fine tune" productivity algorithms for the area

- Determine the spectral contribution of total absorption in photic zone waters due to dissolved organic matter (DOM), phytoplankton pigments, detritus and water which are needed for production algorithm and modeling development and evaluation

- Characterize scalar PAR and the spectral irradiance and radiance fields (both vertical and horizontal variability) for the study region and using the spectral irradiance and radiance fields, calculate surface reflectance $\left(R_{\lambda}\right)$ values which can be used in remote sensing applications

- Examine the $\mathrm{C}$ specific growth rates, $\mathrm{C}$ biomass and pigment biomass for the phytoplankton communities in the study region and determine how these contribute to trophic interactions and exchanges of $\mathrm{C}$ within the shelf ecosystem

- Examine the relationship between fluorescence, extracted chlorophyll and total particulate $\mathrm{C}$ within the study region to enable use of in vivo fluorescence as a proxy index for chlorophyll and particulate organic carbon (POC) 
DISCLAIMER

This report was prepared as an account of work spoosored by an agency of the United States Government. Neither the Uaited States Governmeat dor any ageacy thereof, nor eny of their employees, makes any warranty, express or implied, of essumes any legal liability or responsibility for the sccuracy, completeness, or usefulness of any information, apparatus, product, or process disclosed, or represents that its use would not infringe privatefy owned rights. Reference herein to any specific commercial product, process, or service by trade aame, irademark, manufacturer, or otherwise does not necessarily constitute or imply its endorsement, recommendatioa, or favoring by the United States Government or any agency thereof. The views and opinions of authors expressed herein do not necessarily state or reflect those of the United States Goverament or any agency thereof. 


\section{DISCLAIMER}

Portions of this document may be illegible in electronic image products. Images are produced from the best available original document. 
- Use the above, in conjunction with other OMP PIs, to develop improved models for the primary production and biomass fields using shipboard and mooring information

- Use the above, in conjunction with other OMP PIs, to develop models for the trophic exchanges and transformations of $\mathrm{C}$ in this shelf ecosystem

We can, in conjunction with other OMP PIs, use the information obtained as we address each of these tasks to both calibrate data obtained from the instrumented array of moorings and to help place the mooring-based results within an ecological and biogeochemical cycling context.

Many of the tasks listed above have been completed. Others aspects of the research project are being continued under funding from the NSF U.S. JGOFS Synthesis and Modeling Program. The parameters have been evaluated for the whole phytoplankton community and for the $<8 \mu \mathrm{m}$ size fraction. We have completed data sets for primary production from both experimental approaches (simulated in situ incubations and P-I parameter-based models). In addition, fluorometric chlorophyll, HPLC pigments, POC and PN, and suspended particulate matter (SPM) have all been fully processed. It should be pointed out that we were the only OMP project to provide direct measurements of primary production in the field program. We have examined the relationship between in vivo fluorescence and measurements of both chlorophyll and POC and have found that in vivo fluorescence can be used to reliably estimate the other two parameters. We are continuing to examine the degree of temporal and spatial variability in these relationships. Spectral irradiance and radiance data have been processed and we have examined the relationship between surface reflectance ratios, similar to those which will be employed with the SeaWiFS ocean color satellite, and chlorophyll concentrations at the surface determined by fluorescence methods. We have also processed the spectral absorption and attenuation data obtained in situ with the WET Labs ac-9 and made comparisons with data measured in the shipboard laboratory with spectrophotometric techniques which measure absorption of materials collected onto GF/F glass fiber filters. Under our NSF funded project, we will use these data in conjunction with various production algorithms to improve our ability to model production over the spatial extent of the study region.

During the Spring cruise, primary production ranged from 0.6 to $0.65 \mathrm{gCm}^{-2} \mathrm{~d}^{-1}$ with $52-62 \%$ of the production attributed to the $<8 \mu \mathrm{m}$ size fraction. Growth rates for the whole phytoplankton community and the $<8 \mu \mathrm{m}$ size fraction were low $\left(0.03-0.1 \mathrm{~d}^{-1}\right.$ and $0.09-0.18 \mathrm{~d}^{-1}$, respectively). Phytoplankton carbon represented $50-90 \%$ of the POC; most of the phytoplankton carbon was attributed to the $<8 \mu \mathrm{m}$ size fraction. Dominant pigments included those generally associated with diatoms with a minor contribution due to dinoflagellates and prasinophytes (diatoms: chlorophyll $a$, chlorophyll $c_{1}$ and $c_{2}$, diadinoxanthin and fucoxanthin; dinoflagellates: diadinoxanthin and peridinin; prasinophytes: prasinoxanthin). During the Summer cruise, primary production was more variable than during Spring, ranging from $0.38-2.09 \mathrm{gCm}^{-2} \mathrm{~d}^{-1}$ with $41-83 \%$ of the production attributed to the $<8 \mu \mathrm{m}$ size fraction. Phytoplankton growth rates were generally greater during the Summer than in Spring, with rates ranging from 0.07-0.56 $\mathrm{d}^{-1}$ for the whole community and $0.04-0.84 \mathrm{~d}^{-1}$ for the $<8 \mu \mathrm{m}$ size fraction. During Summer, phytoplankton carbon represents only $30-55 \%$ of the POC, with most of the phytoplankton carbon in the $<8 \mu \mathrm{m}$ size fraction. Phytoplankton pigments were dominated by chlorophylls $a, c_{l}$ and $c_{2}$ and 19'butanoyloxyfucoxanthin, indicative of the importance diatoms and prymnesiophytes. 
Our efforts to generate primary production estimates based on P-I parameters and the use of biooptical models have been completed. We have estimates of the P-I parameters from each station and are in the progress of collecting the other essential information (e.g. daily incident irradiance, irradiance vs. depth profiles and chlorophyll vs. depth profiles) that allowed us to implement the models and produce estimates of production which can be compared to those obtained from the 24 hour simulated in situ incubations. Areal maps of chlorophyll and primary production have been generated and compared to data from specific stations. These maps have also been evaluated relative to AVHRR and subsequent SeaWiFS remotely sensed data.

We have assessed spectral total absorption using 2 different approaches - the WET Labs ac-9 and the quantitative filter pad method. The ac-9 generates profiles of spectral total absorption, beam attenuation and scattering at each of $9,10 \mathrm{~nm}$ wide bands that are the same as those used in the recently launched SeaWiFS satellite imager. Thus, the data will also be of use as we examine our results with an eye toward development of region specific productivity algorithms that would be of use in remote sensing applications. In addition to the distributions of absorption and attenuation which we have obtained using the ac-9 we will, with use of ambient chlorophyll concentrations and P-I parameters, be able to determine, using a published algorithm, values of pigment specific absorption $\left({ }^{*}\right.$ ph $)$ and the quantum yield for photosynthesis $(\phi)$. We anticipate that values of $\phi$ will be useful in the generation of primary production estimates using an alternative modeling approach, giving us a third set of production estimates for the Cape Hatteras study region. Alternatively we will derive values of $a^{*}$ ph from the quantitative filter pad method. This method will also provide measurements of the absorption due to DOM and particulate detritus. At present, we have completed the initial processing of the ac-9 and the quantitative filter pad data and are currently generating our derived parameters and conducting quality control of the data sets. Our objective is to examine the relationships among the different optical measurements to evaluate the extent to which they are in theoretical agreement, and to relate derived inherent and apparent optical properties to measured distributions of particulate (chlorophyll, POC, PN, SPM) and dissolved (DOC) constituents. This will form the basis of a model of spectral irradiance using particulate and dissolved constituent concentrations as input. Such a model will support efforts to generate synoptic scale maps of primary production in the study area defined by the mooring array.

On each of the cruises, we obtained vertical profiles of downwelling spectral irradiance (14 wavelength bands) and upwelling radiance (wavelength bands) at various stations throughout the mooring array.' From these data, we have calculated values of surface reflectance, $R_{\lambda}$, using our Satlantic Profiling System. These data are similar in nature to those obtained through use of satellite remote sensing and are comparable to those used by the recently launched SeaWiFS satellite. Several ratios of surface reflectance have been identified as potentially useful in generating phytoplankton pigment and production models. We have calculated values for the following ratios: $412 \mathrm{~nm} / 555 \mathrm{~nm}, 443 \mathrm{~nm} / 555 \mathrm{~nm}, 490 \mathrm{~nm} / 555 \mathrm{~nm}$, and $510 \mathrm{~nm} / 555 \mathrm{~nm}$. A first step in model generation has been the correlation of these reflectance ratios and surface distributions of chlorophyll concentrations. Thus far, best results have been obtained using the relationship between the $490 \mathrm{~nm} / 555 \mathrm{~nm}$ and surface chlorophyll concentration for the pooled data set from both cruises. We plan to examine the spatial variability in reflectance ratios in the mooring array 
region and to characterize the relationships between other ratios and both pigment measurements and modeled production.

Under our NSF funded project, we have completed the processing of all data sets and continue to work with other OMP investigators to develop models describing trophic interactions and production and to help relate shipboard measurements with those obtained from the moored instruments. From this combined effort, we will be able to address the overall goals of OMP in a most effective manner.

\section{How This Research Addresses OMP Needs}

The research conducted as part of this project addresses several of the designated OMP programmatic needs in a most direct and fundamental way. As stated above, we are the only project to provide direct measurements of primary production during the 1996 OMP field program. This information will be quite useful as other investigators provide results, such as the time course of variability in ambient $\mathrm{O}_{2}$ concentrations measured with the moored instruments, for comparison or "calibration." The data from this project will, when combined with that of other OMP investigators, help to examine the trophic interactions and biogeochemical cycling of $\mathrm{C}$ in our study region, develop shelfwide estimates of primary production and phytoplankton respiration, provide "calibration" data for measurements of $\mathrm{O}_{2}$ and in vivo fluorescence (and other measurements) obtained from moored instruments and shipboard surveys, and contribute to contribute to the development of $\mathrm{POC}$ and PN budgets.

Trophic Interactions and Biogeochemical Cycling of $\mathrm{C}$ : The water column group of OMP investigators designed and conducted several coordinated experiments during the process cruises conducted in 1996. This project was responsible for measuring size fractionated (total and $<$ $8 \mu \mathrm{m}$ ) primary production, carbon specific phytoplankton growth rates and carbon biomass. This information, when combined with the data on bacterial processes in addition to microzooplankton and mesozooplankton abundance, growth and grazing rates, will help us to develop a coherent model of the flows of $\mathrm{C}$ (and $\mathrm{N}$ ) through the shelf ecosystem.

Shelfwide Estimates of Primary Production and Phytoplankton Respiration: Shelfwide estimates of primary production can be made using a variety of approaches with information provided from the moored arrays and from various OMP projects. Our initial approach will be to implement bio-optical primary production algorithms using in situ optical data and simulated remote sensing reflectance data that we have generated. We also plan to work in conjunction with Z. Kolber (BNL) to use results from the FRR fluorometer to provide high resolution spatial maps of primary production. Our data are required, in this case, to "calibrate" the FRR results in units of carbon fixation. One of our original goals had been to develop bio-optical models for use with SeaWiFS ocean color data. Since this sensor has yet to be launched, we will look for other data sources to use in our algorithm development process, such as airborne LIDAR (F. Hoge, NASA).

We have an opportunity to provide estimates of shelfwide water column respiration due to phytoplankton through interactions with Z. Kolber. His project will provide an estimate of gross primary production for samples analyzed using the FRR fluorometer. Our simulated in situ 
studies of production will provide estimates of net primary production. The difference between these 2 measurements is equivalent to respiration. We will examine the reliability and utility of this approach when both data sets have been fully processed.

Provide "Calibration" Measurements for Moored and Shipboard Instrumentation: Much of the instrumentation that will be used to estimate carbon concentrations and fluxes requires the use of some "conversion factor" or calibration. Our direct measurements of chlorophyll, POC, PN and primary production will be of benefit in this regard. For example, information on temporal and spatial variability in in vivo fluorescence and light can be used to estimate primary production by relating the data to our measurements. In addition, an accurate estimate of the photosynthetic quotient $\left(\mathrm{O}_{2}\right.$ produced $/ \mathrm{CO}_{2}$ fixed) is required to relate net increases in $\mathrm{O}_{2}$ concentrations to units of C.

Development of POC and PN Budgets: During the 2 process cruises, we routinely took samples for POC and PN, SPM, fluorometric chlorophyll and HPLC pigments. These samples were collected during the survey transects and the drifter deployments during both cruises and the data will be added to the sets from other OMP investigators to expand our database so that we can more accurately examine the budgets of these parameters. In addition, much of the information obtained during this project is for samples collected while the drifters moved through that portion of the mooring arrays which has been designated "the control volume." This portion of the array had additional instrumentation that will provide a greater amount of information that will need to be correlated with other direct measurements such as those we obtained in our study. We will work with the other OMP investigators to help examine the patterns of variability in parameters such as $\mathrm{O}_{2}$ and nutrient concentrations, and in vivo and FRR fluorometry.

At the recent OMP PI meeting, the Water Column Processes group discussed possible interactions and collaborations for publication of research results. We developed a plan for at least 9 papers to be written about the results of the drifter study alone. At least 2 of these papers would involve investigators from this project as first author with co-authorship on other papers. A plan was also developed for additional papers to be written on other aspects of the OMP 1996 field study. We would be responsible for at least 4 additional papers using the results of this project. These papers would include other OMP investigators as co-authors. In addition it should be noted that 1 graduate student (Dr. E. D'Sa) from the USM Institute of Marine Sciences has already received his doctorate using results obtained as part of this project and another graduate student (Mr. K. Matulewski) will soon complete his doctoral dissertation using results obtained during the 1996 cruises and another OMP cruise conducted during summer 1994.

Over the past grant year, one that was primarily focused on the 2 research cruises, we were able to publish 3 papers and make a number of presentations using the results obtained during this project. This next grant year will have a primary focus of completing analyses and working with other OMP investigators to begin the task of submitting papers on the results of the 1996 field program. 


\section{Scientific Papers and Presentations Related to This Project}

Papers:

D'Sa, E., S.E. Lohrenz, V.L. Asper and R. Walters. 1997. Time series measurements of chlorophyll fluorescence in the oceanic bottom boundary layer with a multisensor fiberoptic fluorometer. J. Atm. Ocean. Tech. 14:889-896.

Lohrenz, S.E., D.G. Redalje, K. Matulewski and J. Ivey. 1997. Comparison of measured inherent optical properties with estimates determined from reflectance in coastal waters off Cape Hatteras, North Carolina, USA. In: Ocean Optics XIII, Steven Ackelson, Robert Frouin, Editors. Proc. SPIE 2963, 489-494.

Lohrenz, S.E., G.L. Fahnenstiel, D.G. Redalje, G.A. Lang, X. Chen and M.J. Dagg. 1997. Variations in primary production of northern Gulf of Mexico continental shelf waters linked to nutrient inputs from the Mississippi River. Mar. Ecol. Prog. Ser. 155:45-54. (This work was part of our OMP project with M. Dagg and others [DE-FG0292ER61414])

Prasad, K.S., S.E. Lohrenz and D.G. Redalje. 1995. Primary production in the Gulf of Mexico coastal waters using 'remotely sensed' trophic category approach. Contl. Shelf Res. $15: 1355-1368$.

Prasad, K.S., S.E. Lohrenz and D.G. Redalje. Satellite derived estimation of primary production in diverse oceanic regions. J. Mar. Syst., in press.

Workshop Proceeding Volumes:

1997 Bailey, S.W., K. Matulewski, J.E. Ivey, D.G. Redalje and A.D. Weidemann. Variability in the absorption spectra of a coastal diatom. Ocean Technology at Stennis Space Center, Proceedings of the Gulf Coast Section, Marine Technology Society, pp. 12-16.

1997 Matulewski, K.V., D.G. Redalje, S.E. Lohrenz and A.D. Weidemann. The variability in inherent optical properties and its relationship to bio-optical parameters measured in spring and summer water masses off Cape Hatteras, North Carolina. Ocean Technology at Stennis Space Center, Proceedings of the Gulf Coast Section, Marine Technology Society, pp. 152-157.

Presentations (with citations for published abstracts):

1994

Prasad, K.S., S.E. Lohrenz, and D.G. Redalje. Estimation of primary production from satellite derived pigment concentrations in diverse oceanic regions. American Geophysical Union/American Society of Limnology and Oceanography, San Diego, CA. February, 1994. Eos 30:194.

Redalje, D.G. and S.E. Lohrenz. Initial characterization of primary production, photosynthesisirradiance parameters and optical properties for shelf and slope waters off Cape Hatteras, 
July, 1994. Department of Energy, Ocean Margins Program Workshop, Woods Hole, MA. September, 1994.

1995

Redalje, D.G., S.E. Lohrenz and G.L. Fahnenstiel. The interrelationships between growth rates and photosynthesis and environmental factors in a river impacted coastal ecosystem. The Oceanography Society, Fourth Scientific Meeting, Newport, Rhode Island. April, 1995.

Dagg, M., R. Benner, S. Lohrenz, D. Redalje and S. Strom. Assimilation and transfer of carbon in oligotrophic and eutrophic coastal water columns. Summer Gordon Research Conference in Chemical Oceanography, New England College, Henniker, New Hampshire. June, 1995.

Lohrenz, S.E., D.G. Redalje and G.L. Fahnenstiel. Primary production and nutrient processes in the Mississippi River Outflow Region. North Carolina Nutrient Summit, North Carolina Coastal Federation, Raleigh, North Carolina. August, 1995. Invited presentation.

Dagg, M., R. Benner, S. Lohrenz, D. Redalje and S. Strom. Assimilation and transfer of carbon in oligotrophic and eutrophic coastal water columns. Department of Energy, Ocean Margins Program Investigators Workshop, Savannah, Georgia. September, 1995.

1996

Ivey, J.E. and D.G. Redalje. A comparison of a long tube absorption meter to the filter pad technique in two turbid estuaries. Ocean Sciences Meeting, San Diego, California. February, 1996. Eos 76:OS166.

Lohrenz, S.E., D.G. Redalje, K.V. Matulewski, J.E. Ivey and A.D. Weidemann. Comparison of measured inherent optical properties with estimates determined from reflectance in coastal waters off of Cape Hatteras, North Carolina. Ocean Optics XIII, Proceedings of the International Society for Optical Engineering, SPIE - The International Society for Optical Engineering. Halifax, Nova Scotia. October, 1996 (publication citation listed above).

Matulewski, K.V., D.G. Redalje and A.D. Weidemann. The effect of phytoplankton species composition the relationship between absorption at $676 \mathrm{~nm}$ and chlorophyll $a$ concentration. 1996 Ocean Sciences Meeting, San Diego, California. February, 1996. Eos 76:OS167.

1997

Chen, N. and S.E. Lohrenz. Relationship between fluorescence and particulate organic carbon: The effect of sediment resuspension. Mississippi Academy of Sciences, Sixty-First Annual Meeting. February 20-21, 1997, Biloxi, Mississippi. J. Ms. Acad. Sci. 42:64.

Dixson, J.A. and D.G. Redalje. Phytoplankton assemblage in St. Louis Bay, MS: Spatial and temporal variation in the signature pigment to total chlorophyll a ratio. Aquatic Sciences Meeting, American Society of Limnology and Oceanography. February 10-14, 1997, Santa Fe, New Mexico. (Student was funded by this project to work on OMP HPLC and other pigment analyses) 
Dixson, J.A. and D.G. Redalje. Phytoplankton assemblage in St. Louis Bay, MS: Temporal and spatial variations in the ratio of signature pigments to chlorophyll a ratio. Mississippi Academy of Sciences, Sixty-First Annual Meeting. February 20-21, 1997, Biloxi, Mississippi. J. Ms. Acad. Sci. 42:57.

Ivey, J.E., D.G. Redalje and A.D. Weidemann. Spectral absorption of coastal waters using the ac-9 and filter pad technique. Aquatic Sciences Meeting, American Society of Limnology and Oceanography. February 10-14, 1997, Santa Fe, New Mexico. (This student participated on the July, 1996 OMP cruise and helped us to develop analytical protocols for use of our ac-9 in coastal waters)

Lohrenz, S.E., D.G. Redalje, G.L. Fahnenstiel and G.A. Lang. Productivity and nutrient relationships along the river/ocean mixing gradient of the Mississippi River plume. Aquatic Sciences Meeting, American Society of Limnology and Oceanography. February 10-14, 1997, Santa Fe, New Mexico. (This work was part of our OMP project with M. Dagg and others [DE-FG02-92ER61414])

Lohrenz, S.E. and V.L. Asper. In situ time-series observations of episodic resuspension of organic matter in coastal waters. Mississippi Academy of Sciences, Sixty-First Annual Meeting. February 20-21, 1997, Biloxi, Mississippi. J. Ms. Acad. Sci. 42:64.

Lohrenz, S.E. and V.L. Asper. Effects of Hurricane Bertha on bottom water fluorescence and oxygen at a shallow coastal site. The Oceanography Society's 1997 Scientific Meeting. April 1-4, 1997, Seattle, Washington.

Matulewski, K.V., D.G. Redalje and S.E. Lohrenz. The relationship between spectral absorption due to phytoplankton, maximum quantum yield, and blue to red total absorption ratios. Aquatic Sciences Meeting, American Society of Limnology and Oceanography. February 10-14, 1997, Santa Fe, New Mexico.

Matulewski, K.V., D.G. Redalje and S.E. Lohrenz. The relationship between spectral absorption due to phytoplankton, maximum quantum yield, and blue to red total absorption ratios. Mississippi Academy of Sciences, Sixty-First Annual Meeting. February 20-21, 1997, Biloxi, Mississippi. J. Ms. Acad. Sci. 42:57.

Redalje, D.G., S.E. Lohrenz, K.V. Matulewski and J.A. Dixson. Daily variability in primary production during Spring and Summer in the coastal waters off of Cape Hatteras, North Carolina. Aquatic Sciences Meeting, American Society of Limnology and Oceanography. February 10-14, 1997, Santa Fe, New Mexico.

Redalje, D.G., S.E. Lohrenz, K.V. Matulewski and J.A. Dixson. Variability in primary production within a discrete water mass during Spring and Summer in the coastal waters off of Cape Hatteras, North Carolina. Mississippi Academy of Sciences, Sixty-First Annual Meeting. February 20-21, 1997, Biloxi, Mississippi. J. Ms. Acad. Sci. 42:56-57.

Redalje, D.G., S.E. Lohrenz and J.A. Dixson. Daily variability in phytoplankton rate processes and biomass within a discrete water mass. The Oceanography Society's 1997 Scientific Meeting. April 1-4, 1997, Seattle, Washington.

M.S. Thesis and Doctoral Dissertations:

D'Sa, Eurico J. Pigment Dynamics in a Coastal Bottom Boundary Layer and its Relation to the Physical Regime: Measurements Using an in situ Fober-Optic Fluorometer. Ph.D. 
Dissertation. The University of Southern Mississippi, Department of Marine Science. May, 1996.

Lochhead, Vivienne C. Optical Properties and Their Relationship to Pigment Concentrations in Continental Shelf Waters off Cape Hatteras, North Carolina. M.S. Thesis. The University of Southern Mississippi, Department of Marine Science (Thesis was presented and defended, final correction are being completed before final submission of the Thesis). Matulewski, Kenneth V. The Assessment of Variability in Inherent Optical Properties and Their Use in Modeling the Variation in Primary Production in Spring and Summer Water Masses off Cape Hatteras, North Carolina. Ph.D. Dissertation. The University of Southern Mississippi, Department of Marine Science (this Dissertation is in preparation at this time). 